MedieKultur | Journal of media and communication research | ISSN 1901-9726

Article - Theme section

\title{
Researching intimacy through social media A cross-platform approach
}

\section{Cristina Miguel}

MedieKultur 2016, 60, 50-69

Published by SMID | Society of Media researchers In Denmark | www.smid.dk The online version of this text can be found open access at www.mediekultur.dk

\begin{abstract}
This paper aims to contribute to the understanding of how to study the way people build intimacy and manage privacy through social media interaction. It explores the research design and methodology of a research project based on a multi-sited case study composed of three different social media platforms: Badoo, CouchSurfing, and Facebook. This cross-platform approach is useful to observe how intimacy is often negotiated across different platforms. The research project focuses on the cities of Leeds (UK) and Barcelona (Spain). In particular, this article discusses the methods used to recruit participants and collect data for that study - namely, participant observation, semi-structured interviews, and user profiles analysis. This cross-platform approach and multi-method research design is helpful to investigate the nature of intimacy practices facilitated by social media at several levels: online/offline, across different platforms, among different types of relationships, within both new and existing relationships, and in different locations.
\end{abstract}

\section{Keywords}

Cross-platform, Internet, intimacy, methodology, social media use 


\section{Introduction}

This research aims to contribute to the understanding of how to study intimacy practices mediated by social media. I investigate the intimate experiences of social media users, using a multi-sited case study. The research project is composed of the social media platforms Badoo, CouchSurfing, and Facebook in order to observe users' intimacy practices across different platforms in two countries: Spain and the UK. Scholars in a range of disciplines including anthropology, social psychology, cultural studies, feminist studies, and sociology are interested in people's use of technology to keep in contact with significant others at a distance. As Law (2004, p. 3) pointed out, these studies describe "decentred subjectivities and the geographical complexities that arise when intimacy no longer necessarily implies proximity." Following this debate, Rainie and Wellman (2012) argue that networked individualism is the new social operating system by which individuals participate in different networks. This creates a different social structure in which people are geographically dispersed in opposition to traditional local communities. Law (2004) explains how there is a need for qualitative approaches to study this new networked or fluid world, which is highly unpredictable and changeable and cannot be explained in a mathematical sense. In this context, it is useful to refer to boyd's (2010, p. 36) analysis of social network sites as networked publics, "which are simultaneously (1) the space constructed through networked technologies and (2) the imagined community that emerges as a result of the intersection of people, technology, and practice". Hine (2015) suggests the use of different research methods in order to understand how technologies are adapted and adopted in everyday life. Building on Robinson and Schulz (2009), who describe Internet research as increasingly multi-modal (online/offline), Hine (2015) affirms that her research is for the Internet, not through the Internet.

Accepting this view, I conducted a qualitative study based on a multi-sited approach to understand different kinds of intimacy practices facilitated by social media at several levels: across different platforms (Badoo, CouchSurfing and Facebook), multi-modal (online/ offline), and in different locations (UK \& Spain). As Kember and Zylinska, (2012, p. 32) point out, "a multi-sited case study may be useful to capture a holistic picture of a practice." Building on Morgan's concept of "family practices", Jamieson (2012) introduces the term "practices of intimacy" to refer to "practices which enable, generate and sustain a subjective sense of closeness and being attuned and special to each other." My main aim was to study intimacy practices in an integrated fashion; therefore, I used this multi-sited approach. Following boyd's (2010a) concept of networked publics and Rainie and Wellman's (2012) concept of networked individualism, I use the term "network intimacy" to picture the nature of intimacy in the context of social media.

Drawing from feminist epistemology (e.g., Reinharzt \& Davidman, 1992; Stanley \& Wise, 1993; Skeggs, 1995) and using an ethnographic approach (e.g., Rybas \& Gajjala, 2007; Horst \& Miller, 2012; Gómez Cruz \& Ardèvol, 2014; Hine, 2015; Pink et al., 2015), I investigate the intimate experiences of social media users who use these services to interact with new 
and existing relationships. Feminist scholars and anthropologists alike put the process of reflexivity at the centre of the research. Epistemological reflexivity refers to the fact that all knowledge is situated. Stanley and Wise (1993) explain that, as it is unavoidable that a researcher's knowledge is situated, the researcher should make proper use of this situation as a basis of her knowledge in the research project. Skeggs (1995) states that we, as researchers, have a specific social-political-cultural-economic position defined by our gender, class, sexuality, nationality and race that influences every stage of the research from the selection of participants to the interpretation of the data. The researcher's personal identity affects the research practice. In relation to gender, I was aware that my identity as a young female researcher might affect my relationship with participants. In my study, my own identity as a feminist and the gendered context of my fieldwork (especially in reference to Badoo) led me to think reflexively about the role that I, as a female researcher, played in the data collection process.

Another characteristic of feminist and ethnographic research is that the researcher tries to forge a connection between the reader and the people studied. As Rybas and Gajjala (2007) point out, "The first-person autoethnographic narratives breach the separation of researcher and subjects and establish intimacy with the reader as a co-participant of the dialogue." The use of the first person has been part of the feminist project. I use the first person to locate myself in the research project as part of my feminist approach; and, on some occasions, my own experience was used as autoethnography in order to contextualise particular situations. Van Maanen (1998) states that, in "skilled hands", the use of the first person voice in a confessional tale may help to the reader to understand the problematic nature of the fieldwork better.

I used three data collection techniques: participant observation, in-depth interviews, and user profiles analysis. Feminist media scholars conducting ethnographic studies in online settings (e.g., Gajjala, 2003; Orgad, 2005; Senft, 2008; boyd, 2014) use a combination of observation, interviews, and textual analysis. Similarly, I used a combination of those methods. I immerse myself in my three case studies. I logged in regularly. I analysed the characteristics of each platform. Then, I used this expertise to engage with people's experiences through their narratives in the interviews and the analysis of their profiles, which are both representation of their identity and part of their lived experiences. My fieldwork started in March 2013. The first two months were dedicated to immersing myself in Badoo and Couchsurfing and finding participants in Leeds. My primary sources were interviews with participants, my field notes, and the social media platforms themselves - with the focus on participant user profiles. The data gathered through these techniques were subsequently analysed thematically. It is widely accepted that research participants must have their right to privacy, confidentiality, and anonymity protected; and, as Lee \& Renzetti (1993) note, this is especially important in research that involves the disclosure of intimate information. Confidentiality and anonymity were guaranteed to all participants in order to protect their privacy. 
In this article, I first present my research design, which is built around a multi-sited case study using an ethnographic approach. Second, I introduce my methods for recruiting participants and data collection techniques, which include participant observation, interviews, and user profiles analysis.

\section{Research design: Multi-sited and cross-platform}

The concept of multi-sitedness was mainly developed by Massey (1992) and Marcus (1995). Multi-sited research, Hine (2015, p. 61) notes, is characterised by "connection and mobility rather than static location". Drawing on Büscher and Urry, Hine (2015, p. 63) explains that there is a body of research interested in analysing mobility, which includes "virtual travel across networks of meditated communications; and communicative travel as people are connected in interactions face-to-face and via mediated communications." In a recent study about the use of media by young people, Studying Youth in the Media City: Multi-sited Reflections by Sumiala et al. (2014), the authors also apply the term to the study of both online and offline interaction. Moreover, they study the use of media by young people in different locations around cities in two countries (Finland and the UK) and through different online platforms. Following Falzon (2009), Sumiala et al. (2014) used a multi-sited research design that not only relates to different places but also includes cross-platform and multi-modal perspectives in order to approach the inherently mutable character of the studied phenomena. My research design is very similar to the one used by Sumiala et al. (2014); it is multi-sited at different levels: cross-platform, multi-modal, and participants were located in two countries.

This study explores the intimate experiences facilitated by social media, using a crossplatform case study composed of three social media platforms: Badoo (dating/hookup site), CouchSurfing (hospitality exchange/meetup network), and Facebook. Merriam (1998) defines a case study as descriptive, heuristic, and inductive. On the other hand, a case study, as defined by Yin (2009, p. 18), is "an empirical enquiry that investigates a contemporary phenomenon in depth and within its real-life context." According to Yin (2009), case studies usually answer what?, how?, which?, and why? research questions. Following Heriott and Firestone, Yin (2013) emphasises that the evidence from research that uses multiple case studies is often more compelling and robust. Drawing on ethnographic perspective, I try to picture how users appropriate different social media services in their search for intimacy. This cross-platform approach helps to map and understand the complexity of the current social media ecology, which Couldry (2011) calls "media manifold".

In this context of multiple communicative opportunities, Madianou and Miller (2013, p. 172) introduce the concept of "polymedia" to emphasise the way users choose among different affordances offered by different media to negotiate different kinds of personal relationships: "Polymedia is not simply the environment; it is how users exploit these affordances in order to manage their emotions and their relationships." I also pay attention to 
how the architecture and policies of Badoo, CouchSurfing and Facebook shape the way people communicate and how different social norms emerge through time and experience in each setting. The objective is to understand how users create and maintain different kinds of relationships through different platforms by navigating the affordances and norms of social media platforms.

The Badoo and CouchSurfing websites allow users to create and develop personal relationships. This research design helps to analyse the kind of intimate interactions facilitated by these platforms both online and offline. Facebook, as the mainstream social networking service, is used to observe how users migrate the interaction from Badoo and CouchSurfing to Facebook and how these users negotiate intimacy within both new and existing relationships on this platform. Thus, the study explores the migration of the communication within relationships that started online to other platforms or face-to-face encounters. The hybrid nature of intimacy practices, which may start online or offline and develop through one of the two settings (or both), as Gómez Cruz \& Ardèvol (2013) note, is acknowledged through this multi-sited approach.

This qualitative study is mainly based on in-depth semi-structured interviews. Some scholars (e.g., Turkle, 1996; Markham \& Baym, 2009) affirm that it is useful to conduct face-to-face interviews with people studied online in order to explore individual's life stories and the role technology plays in their personal relationships. In my research, after an initial phase of immersion to get to know the platform characteristics and rules and to find participants, I then interviewed users. Later, I gathered user profiles; and, finally, I analysed user profiles and the interview data thematically. I decided to conduct user profiles analysis after the interview, as I wanted to be sure that participants understood the research objectives and signed the consent form. My fieldwork lasted from March 2013 to February 2014. The first two months were dedicated to immersing myself in Badoo and CouchSurfing and to finding participants. The interviews took place in 4 different waves: May and August in Leeds, and September and December in Barcelona. January and February in 2014 were dedicated to negotiating with participants, gathering user profiles and concluding the participant observation. In the next section, I will explain in more depth how I selected participants and how I engaged with them.

\section{Recruiting participants}

Participants were identified as members of either CouchSurfing or Badoo (or both) in Leeds (UK) and Barcelona (Spain). The focus of the research was adult social media users; nevertheless, I did not look for any particular class or national background (i.e., only British and Spanish). It happened that people who were willing to participate in the research were from different nationalities and with different occupations, including unemployed participants, students, and professionals. The research targeted adults aged 25-49 (although the oldest participant was actually 47 years old). My focus was on adults because there are 
already plenty of studies about intimacy practices among teenagers and college students and few about adults.

I selected the locations of Leeds and Barcelona because they are large cosmopolitan centres and it is easy to find people who use social media to create new relationships. The cosmopolitan and multicultural nature of these locations, which have a large number of mobile inhabitants who live there for a short-medium period of time, made them suitable for finding people who decided to look for new personal relationships through social media. In addition, I chose these two locations for practical reasons, such as the possibility of getting access to users of CouchSurfing (I belonged to local CouchSurfing communities in both Barcelona and Leeds) and the possibility of communicating with participants in their own language, as I am fluent in English, Spanish, and Catalan. Nevertheless, since many participants were expats, I conducted interviews with people whose mother language was not one of the aforementioned languages. I cannot describe this study as culturally comparative research between England and Spain because, in both countries, participants were from a wide range of nationalities.

The study included fifteen participants based in the UK, twelve of whom were CouchSurfing users, seven of whom were Badoo users, and all of whom were Facebook users. Twelve of them friended me on Facebook. The other fifteen participants were based in Spain, nine of whom were CouchSurfing users and ten of whom were Badoo users. All participants based on Spain were Facebook users, and thirteen of them friended me on Facebook for the study. Participants were not required to give their legal names or other information that could identify them, such as address or date of birth. Anonymity was ensured; participants were given pseudonyms. They were asked to give their age, gender, and nationality; and these three variables were used to identify them as subjects of the study. Table 1 shows the distribution of participants by country and site.

One of my first concerns was the negotiation of my position as insider or outsider with respect to the community being researched. Following Finch (1993) and Skeggs (1994), Watts (2006) affirms that being an insider familiar with the culture of the industry was useful; she already understood the industry she was researching. Speaking the same language as participants is helpful in order to build rapport. Similarly, I was a member of all the social media platforms that have informed my study since 2007/2008, although I had barely used Badoo. For the purpose of the research, I created academic accounts on these three social media platforms and presented myself as a researcher. Nevertheless, I decided to keep using my CouchSurfing personal account because I have a good reputation on the platform, since I have a number of positive references from my past interactions with other users. I included in my personal description that I was a researcher. On CouchSurfing, I was an insider. I already spoke the same language as the other couchsurfers, and I benefited from my prior connections in conducting the research. On the other hand, as Hine $(2015$, p. 85$)$ notes, insider status may also be problematic: "Being an insider presents some problems in 
Article: Researching intimacy through social media

\begin{tabular}{|c|c|c|c|c|c|c|}
\hline Participant & Gender & Age & $\begin{array}{l}\text { Country of } \\
\text { Residence }\end{array}$ & CouchSurfing & Badoo & Facebook \\
\hline Vanessa & female & 29 & Spain & $\mathrm{x}$ & & $\mathrm{x}$ \\
\hline Patricia & female & 31 & Spain & & $\mathrm{x}$ & $\mathrm{x}$ \\
\hline Ivana & female & 32 & Spain & $\mathrm{x}$ & (x) & $\mathrm{x}$ \\
\hline Raquel & female & 35 & Spain & $\mathrm{x}$ & $\mathrm{x}$ & $\mathrm{x}$ \\
\hline Sara & female & 39 & Spain & $\mathrm{x}$ & & $\mathrm{x}$ \\
\hline Olga & female & 40 & Spain & $\mathrm{x}$ & & $\mathrm{x}$ \\
\hline Laura & female & 41 & Spain & & $\mathrm{x}$ & $\mathrm{x}$ \\
\hline Gemma & female & 42 & Spain & $\mathrm{x}$ & & $\mathrm{x}$ \\
\hline Petro & male & 28 & Spain & & $\mathrm{x}$ & $\mathrm{x}$ \\
\hline Luis & male & 30 & Spain & $\mathrm{x}$ & $\mathrm{x}$ & $\mathrm{x}$ \\
\hline Esteban & male & 35 & Spain & $\mathrm{x}$ & & $\mathrm{x}$ \\
\hline Ramon & male & 37 & Spain & & $\mathrm{x}$ & $\mathbf{x}$ \\
\hline Viel & male & 38 & Spain & $\mathrm{x}$ & (x) & $\mathrm{x}$ \\
\hline Marc & male & 39 & Spain & & $\mathrm{x}$ & $\mathrm{x}$ \\
\hline Cesar & male & 44 & Spain & & $\mathrm{x}$ & $\mathbf{x}$ \\
\hline Noelia & female & 25 & UK & $\mathrm{x}$ & & $\mathrm{x}$ \\
\hline Lulu & female & 25 & UK & $\mathrm{x}$ & & $\mathrm{x}$ \\
\hline Caroline & female & 26 & UK & $\mathrm{x}$ & & $\mathrm{x}$ \\
\hline Alice & female & 28 & UK & $\mathrm{x}$ & & $\mathrm{x}$ \\
\hline Ana & female & 35 & UK & $x$ & $\mathrm{x}$ & $\mathrm{x}$ \\
\hline Sandra & female & 39 & UK & & $\mathrm{x}$ & (x) \\
\hline Isaac & male & 26 & UK & $\mathrm{x}$ & $(\mathrm{x})$ & $\mathrm{x}$ \\
\hline John & male & 28 & UK & $\mathrm{x}$ & & $\mathrm{x}$ \\
\hline David & male & 30 & UK & & $x$ & $\mathbf{x}$ \\
\hline Peter & male & 32 & UK & $\mathrm{x}$ & & $\mathrm{x}$ \\
\hline Mario & male & 36 & UK & $\mathrm{x}$ & & $\mathrm{x}$ \\
\hline Oscar & male & 41 & UK & $\mathrm{x}$ & & $\mathrm{x}$ \\
\hline Robert & male & 43 & UK & $\mathrm{x}$ & $\mathrm{x}$ & $\mathrm{x}$ \\
\hline Gary & male & 43 & UK & & $\mathrm{x}$ & $\mathbf{x}$ \\
\hline Mateo & male & 47 & UK & $\mathrm{x}$ & (x) & $\mathrm{x}$ \\
\hline
\end{tabular}

Table 1. Distribution of participants by country and site

* In parenthesis: deleted profiles

**In bold: profiles not provided by participants 
developing an appropriate positioning and retaining the ability to question the taken-forgranted." In order to overcome this issue, Hine (2015) recommends thinking of the familiar as strange again. In this sense, I questioned the motivations users had to join CouchSurfing and how personal relationships are developed through the platform.

I used convenience sampling to find participants through a one-to-one approach (including my personal network) and a call for participants. Alan Bryman (2012, p. 201) explains that "convenience sampling is one that is simply available to the researcher by virtue of its accessibility." Following Dörnyei (2007), Farrokhi (2012, p. 784) defines convenience sampling as "a kind of non-probability or nonrandom sampling in which members of the target population are selected for the purpose of the study if they meet certain practical criteria, such as geographical proximity, availability at a certain time, easy accessibility, or the willingness to volunteer." Thus, the participants in this study are CouchSurfing or Badoo users (25-49 years old) located in Leeds or Barcelona who were willing to take part in the study.

In the case of Badoo, I had to contact (potential) participants one by one through the chat feature as there are no groups or other means of public communication to address users. This technique was very time-consuming since most male users were interesting in flirting with me instead of participating in the research. Nevertheless, finding female Badoo users who wanted to take part in the study was the hardest task. Once I completed the interviews with male participants, I specified in my Badoo profile that I wanted to chat only with women although this did not prevent men from contacting me. I got few messages from women, and they were only interested in dating - apart from the two women who agreed to the interview through this approach. Thelwall (2011) suggests that women are more concerned about their privacy online because they post more personal information than men. In addition, the fact that the practice of meeting people online is still stigmatised (e.g., boyd, 2010b; Hine, 2014), along with the general belief that meeting strangers online is dangerous, may have contributed to the difficulty in finding female Badoo participants. Thus, I had to use my personal network to find more female participants who were Badoo users.

In the case of CouchSurfing in the UK, I spread the call for participants through the "Leeds" group and through other smaller groups of general interest, such as "Language Exchange". I also spread the call for participants through the "Leeds CS Events" Facebook group, which is the mirror of the "Leeds" CouchSurfing city group on Facebook. I discovered during the fieldwork in Leeds that it was common for some participants to be users of both CouchSurfing and Badoo. Thus, I also looked for participants who were users of both sites by posting a call for participants in different CouchSurfing groups in Barcelona. Despite all this effort to find participants through a call for participants, I recruited half of the participants through my personal network. I e-mailed CouchSurfing members that I had as friends on Facebook to ask them to participate in the research project, but most people contacted were reluctant to participate in the study. Attending meetings with 
CouchSurfing people was the most effective way of getting participants for the research because they could ask me questions face-to-face and get to know better the objectives of the study. I could also explain to them in detail that all the information provided would be confidential and anonymous. Couchsurfers were not familiar with research ethics, and I had to assure them that they could be completely confident that all the information provided would be kept in the strictest confidence, and I explained to them that my research proposal had already passed the ethics board of my university. In this sense, the face-to-face interaction was needed to address any concerns that potential participants may have had in a more direct way.

A common controversy in the process of selecting the sample is whether it is better to interview strangers or people we already know. Reinharz and Davidman (1992, p. 26) analysed the process of recruiting participants in several research projects, and they found that some scholars claimed that "they needed to have close relationships before the interview took place". Likewise, some scholars explained that some participants refused to take part in research due to the "lack of relationship". On the other hand, other scholars claimed that interviewing strangers may lead to more self-disclosure. I included known people in the study in order to overcome the difficulty of finding "strangers" to participate and to find a balance in the types of participant I was recruiting. Most "stranger" participants identified themselves as "very open". For this reason, their concept of intimacy was quite different from those who would not have participated in the research if they had not known me in advance. In fact, one CouchSurfing user explained during the interview that she had seen the call for participants in April 2013 but, because she did not know me at that point (we met in May 2013 at a meeting), she did not reply. She asked me about the recruiting process and the object of the study at the end of the interview. We discussed the fact that, if I had recruited only through a call for participants, many introverted people like her (as she characterised herself as shy) would not have been present in the research. Hine (2015) notes that a general call for participants often produces a limited number of volunteers; for this reason, more targeted approaches to explain the objectives of the study are usually more effective than general appeals. In the case of Badoo, I had to contact (potential) participants one by one through chat since there are no groups or other means of public communication to address users. This technique was very time-consuming.

I decided from the beginning to offer participants a drink in exchange for collaborating in the research - not only because of the time involved in taking part in the interview, but also because I sometimes conducted the interviews in cafes and I did not think that it was fair for them to spend money to participate in the research. Borgatti and Molina (2005) explain how it is fair to give rewards to participants to compensate them for their time and avoid exploitation. Wiles (2013) highlights that the issue of "rewarding participants" has been subject of debate because rewards can be seen as an element that compromises freely-given consent, but she also acknowledges that rewards may simply be fair recompense for the time and energy employed in the study. 
The process of looking for participants and the ongoing relationship with them were a very important part of the research process. Following feminist scholars (e.g., Reinharzt \& Davidman, 1992; Skeggs, 1995) and anthropologists (e.g., Rybas \& Gajjala, 2007; Hine, 2015; Pink et al., 2015), I reflected in the research process to acquire knowledge. I took regular field notes to use the process of recruiting participants as (participant) observation to understand the nature of the relationships that different sites foster. In the next section, I shall explain in more depth how I conducted the observation.

\section{Participant observation}

In feminist research generally, participant observation, Reinharz and Davidman (1992, p. 68) point out, is valued because it forges a personal connection with participants insofar as it fosters "openness to intimacy and striving for empathy, which should not be confused with superficial friendliness." In addition, in media studies, as noted by Kember and Zylinska (2012), participant observation involves engaging in everyday activities and recording and analysing those activities. Researchers usually record their observation through field notes. Hine (2015, p. 74) explains that field notes allow the researcher to record what happens, but also help to develop further insights in the research project insofar as field notes are helpful "to capture her provisional thoughts about what these observations may mean, her ideas about what to look at next, and her concerns about aspects that puzzle or frustrate her."

Observational methods have been extensively used to study media use. For instance, Walkerdine (1986) in Video Replay: Families, Films and Fantasy observed how a working family watched the film Rocky II. By using participant observation, she attempted to analyse the constitution of subjectivity within a variety of cultural practices, such as watching videos, and plunged into her own life memories from when she was a child in order to help her to describe different aspects of family life in the context of popular culture. Horst and Miller (2011) are also a good example of the extensive use of participant observation in their study about the use of Facebook by people from Trinidad. They observed participants in their homes or workplaces interacting online with other users. They mainly used this method to observe the different contexts in which Trinidadians engaged in Facebook interaction and the different meanings Facebook use had for them.

In my research, participant observation had two phases: the immersion phase in which I also started looking for participants and the interaction phase with participants during and after the interviews. First, I immersed myself in both Badoo and CouchSurfing and conducted participant observation in March-April 2013. I positioned myself as observer participant. Berg (2009, p. 81) affirms that, when they perform the role of participant observer, researchers "move away from the idea of participation but continue to embrace the overt role as investigator." Thus, I disclosed through my profile that I was a PhD student conducting research about intimacy practices through social media and that I was using the site as one of my case studies. Online participant observation allowed me to acquire expertise 
about the characteristics of each platform, its regulations, the verification systems that Badoo and CouchSurfing provide, and the paid premium services available in Badoo to acquire more visibility or to be able to contact more users. Apart of analysing the workings of platforms and users profiles, I draw on my own experience as a user of these platforms to contextualize and deepen the analysis. The key idea, as observed by Hine (2009, p. 4), is that "the researcher should become immersed in the social situation being studied and should use that experience to try to learn how life is lived there."

Markham (1998) in her research about virtual environments noted that online participant observation allowed her to learn about the values and sociality norms of communities. Likewise, in the process of looking for participants, interaction with other users through Badoo helped me to understand how the site works, shared social practices and the nature of the interaction on the site. Like Miller and Slater (2000), I discovered that some Badoo users have several accounts in order to be able to contact more users without having to pay premium services. In the case of CouchSurfing, I was already familiar with the practices and the social norms; but, as Hine (2015) recommends, I engaged in the exercise of thinking the familiar as strange again to acquire a deeper understanding of the phenomenon. I took field notes, personal reflections and observations to describe things about which I had become aware throughout the day, and I recorded chat conversations with Badoo participants. As Hine (2000, p. 13) reported in Virtual Ethnography, these regular conversations signified the "rich insight of their involvement."

Participant observation was also useful during the course of the interviews to explain the context of the interview and the participant's behaviour. After the interviews, I kept in contact with participants through Badoo or CouchSurfing sites in order to try to friend them on Facebook. Some Badoo participants often talked to me if they saw me online in Badoo or Facebook. I checked their user profiles in the different networks once a week during a period of three months after the interviews in order to get more insight in their social media practices, and I continued taking field notes. I will explain more in detail the process and craft of the interviews in the next section.

\section{Semi-structured in-depth interviews}

Although I used other data collection techniques, interviews played a central role in my research process. Semi-structured in-depth interviews are useful to explore people's life experiences from their own point of view. Thus, Reinharz and Davidman (1992, p. 19) affirm that "interviewing offers researchers access to people's ideas, thoughts, and memories in their own words rather than in the words of the researcher". Likewise, Hine (2015, p. 78) points out that interviews are "a way of delving into a specific informant's experiences and understandings". Therefore, the interviews focused on gathering information about online mediated intimate experiences and the encounters that may be experienced as a result of these interactions. Although, as Hine (2015) points out, a semi-structured interview follows 
a guide, the researcher adds questions to aid the narrative of the interviewee, which allows the exploration of emerging topics.

The interviews lasted between forty-five minutes and two and a half hours, and they were audio-recorded. I conducted 30 interviews. 15 interviews were carried out in Leeds (UK) in May and August 2013, and 15 in Barcelona (Spain) in September and December 2013. In Barcelona, I looked for participants only one week before I went there, but I had learned in the process of the research in Leeds that I had to schedule the interviews as soon as possible after making the contact in order not to lose the interest of (potential) participants. Although most interviews were conducted face-to-face, I also conducted two interviews online through Badoo chat with two UK participants. It might seem that conducting interviews online is the best setting to conduct research about social media interaction; however, online interviews have advantages and disadvantages. In my study, I felt that the information I was gathering through online interviews was poorer than that gained from face-to-face interviews; participants seemed less engaged and gave less elaborate answers. Therefore, I decided not to conduct more interviews online.

In general, establishing a date and time for interviews was more complicated than I expected. For instance, one CouchSurfing participant changed the date of the interview six times. The setting of an interview is very important. In her study about the use of MySpace by teenagers, boyd (2014) explains that finding a place where participants feel comfortable to share their stories is paramount. Sin (2003) conducted research about how the place where the interview is conducted affects the construction of knowledge. Interviews are - at least, in part - structured by the spatial context in which they are conducted. At the same time, the production of information through the interactional interview can affect the experience and understanding of the socio-spatiality of the interview site. I conducted the interviews in a vast array of settings. I interviewed all CouchSurfing participants in their homes because I felt safe, as I already knew some of them or they had positive references in their profiles. On the other hand, I usually interviewed Badoo participants at coffee shops or at the university due to safety concerns. Thus, although interviewing all participants at home would have been ideal for getting them to open up, I conducted half of the interviews in public spaces for practical and security reasons.

Participants were given information sheets and consent forms before interviews began. Alternatively, at the beginning of the recording of the interview, I explained verbally to the interviewee the same information contained in the consent form and her/his consent was recorded. Some participants asked me some questions in relation to anonymity, and I explained that all the information was anonymised, that I would never use their real name or any information that might identify them. This affirmation usually helped to build rapport. As Kember and Zylinska (2012) noted, being trusted by the interviewee is essential to develop rapport. Feminist research often includes a strong connection between the researcher and participants. I tried to keep eye contact all the time, and I rarely took notes during the interview. Instead, I usually described whether the participant was engaging in 
some kind of non-verbal communication, and I asked them to explain what they meant by this or that gesture. Thus, through these various strategies, I tried to build trust and rapport. In addition to being a matter of ethical concern, as feminist researchers, such as Finch (1993) in her playgroup study, note, the comfort of the interviewee has a direct impact on what participants feel able to speak about during the interview.

Before the interviews, participants were asked to fill out a pre-info sheet in order to collect some demographic information and other data such as political affiliation and alcohol intake. Then, I asked them to indicate which data they considered intimate and which they revealed in their social media profiles. Thus, the objective of the pre-info sheet was to identify what kind of information participants considered intimate and which of this information they share in their CouchSurfing, Badoo or Facebook profiles. It also gathered some details about their social media activity: names of platforms they used, years of use, main purpose, and regularity. After participants finished completing the pre-info sheet, I started to tape-record the conversation, beginning with questions about how participants first heard about CouchSurfing or Badoo. Reinharz and Davidman (1992) explain that the use of simple questions is a good technique that functions as an ice-breaker and helps to establish rapport. During the interviews, participants were asked to comment on questions with as little interruption as possible. However, if the informant's response was too brief or ambiguous, then I raised additional questions in order to reach a more in-depth understanding of the participant's comments. In designing the interviews, I tried to avoid directing the participants towards determinate types of answers. For instance, when inquiring about privacy online, I asked, "Have you ever thought about privacy online?" instead of asking, "Do you think that privacy is diminished online?"

The primary ethical obligation of any research is to avoid causing harm (e.g., Hine, 2000; Ess \& AolR Ethics Working Committee, 2002; Cooper, 2007; Markham \& Buchanan, 2012). Research would be considered harmful, for instance, if it generates any kind of mental distress or embarrassment for the participants. The potentially sensitive topic of the research project, which deals with intimacy practices, is an ethical issue itself. Especially during the interviews, I took care that the participants felt comfortable because talking to people about their intimate experiences involves feelings, and it is important to be sensitive to the reaction of the participants to the questions and to change the topic, take a break, or conclude the interview if the participant was uncomfortable. Of course, participants were not forced to reveal any information they did not want to provide. Cooper (2007, p. 243), following Gilligan's (1995) work in feminist ethics of care, highlights the importance of taking care of participants in feminist research: "Care has become a central frame for feminist scholarship, providing a primary term through which intimacy and labour are configured." Thus, I was very careful to formulate all questions in a respectful way, and I changed topics if I observed any signal of distress. Only once did a participant look uncomfortable while talking about her personal relationships. Therefore, I moved on to some technical ques- 
tions that were related to the configuration of privacy settings in the social media platforms she used.

Some scholars (e.g., Sieber, 2010; Gray, 2009) affirm that not only do researchers have to avoid causing any harm, but they also should aim to provide positive benefits to participants. In the research, participants benefited from a better understanding of how they negotiate their intimate relationships through different social media platforms. In fact, one participant commented after the interview that he had never thought of his practices in such a deep way. He stated that his better understanding of his own intimacy practices through social media was a positive outcome of participating in the research. My main objective when conducting research from this ethical point of view was avoiding harm; nevertheless, I always tried to help participants with my knowledge of social media to help them make sense of their own intimacy practices when interacting online.

Participant's narratives during the interviews were used to explore both online interactions and offline intimate encounters facilitated by the use of those platforms. After the interviews, as explained earlier, I took some field notes about the interaction, focusing on participants. I also looked at user profiles to check that the information reported to be in the profile was actually online. In addition, I analysed user profiles to examine how each interface fosters a particular kind of self-disclosure and how users navigated the features of the social media platforms to (re)present themselves in the network. I present the user profile analysis below.

\section{User profile analysis}

Communication through social media platforms can be synchronous or asynchronous. Hogan (2010) examines the temporal dimension of social media communication from a symbolic interactionist perspective and argues that self-presentation through social media platforms is composed of performances and artefacts. Performances take place in "situations", while artefacts take place in "asynchronous" exhibitions. Goffman's self-presentation and symbolic interactionism theories have been used by several scholars (e.g., Miller, 1995; Sannicolas, 1997; Ellison et al., 2006; Hogan, 2010; Kalinowski \& Matei, 2011; Wessels, 2012) to examine online identity and digital communication. Applying Goffman's dramaturgical theory while studying interpersonal communication in face-to-face interactions, Hogan (2010) suggests that, in social media interaction, we should consider the user as an actor only in synchronous communication. Thus, Hogan argues that the actor performs in real time in "situations", and recordings of past performances are actually artefacts (e.g., photos, status updates, comments) that users exhibit through their profiles. User profiles are cultural artefacts because, as Reinharz \& Davidman (1992) stated, cultural artefacts are narratives and visual texts produced by people. One of the main characteristics of cultural artefacts is that they are not created ad hoc for the research project. Reinharz and Davidman (1992, p. 147) noted that cultural artefacts "possess a naturalistic, 'found' quality 
because they are not created for the purpose of the study". User profiles remain in servers for a long period of time; for this reason, they may be considered as archives of affect (Gehl, 2013) or feelings (Ferreday, 2013). Building on Kuntsman, Ferreday (2013, p. 56) points to the usefulness of analysing user profiles to understand "the specificities and contingencies of online and offline life". Following this concept of user profiles are artefacts that already exist, I just copied and pasted the content I was interested in analysing in a Word format.

For ethical reasons, I conducted user profile analysis after the interviews when I received the signed consent of the participants. In their research about user perspectives on Internet research, Beninger et al. (2014) found that there is no agreement among users about the need to ask for consent in Internet research, since some users believe that the information is publicly available. In particular, Beninger et al. (2014, p. 28) identified a range of factors that social media users consider important to ask for consent in Internet research: "Mode and content of the posts; Social media website being used; The expectations the user had when posting, and; The nature of the research". In particular, social media users explained that the sensitivity of the content (e.g., if a social media site was particularly sensitive or personal), it is fundamental to ask for permission from the participants. Therefore, due to the sensitive nature of my research topic, I considered it necessary to ask for the consent from all the participants before analysing any digital data.

Following Ong, Ess (2012) explains that social media platforms reintroduce some characteristics of the orality in the communication landscape, expanding the auditory as well as the visual. They claim that the sense of selfhood is changing in the culture of connectivity, and Western cultures are moving from an individualistic sense of privacy toward "group privacy", which would be located in the boundary between public space and individual privacy. Ess (2012, p. XVII) connects this idea of new relational and emotional senses of selfhood with the emergence of virtue ethics in the context of online communication (e.g., child pornography). In relation to information gathered from user profiles, although information published in social media is considered public by many people, there are different expectations of privacy in public, which Ess (2012) considers "group privacy". Thus, this was one reason for not analysing information produced by the participants' friends in their profiles. Nissenbaum (2010) has also developed a framework to explain how different people have different expectations of privacy that are culturally and contextually shaped, called contextual integrity, which can be applied to online settings. As we cannot know the expectation of privacy the participants (or their friends) have, the best ethical approach is to assume they all have high expectations of privacy.

I gathered all "profile pictures" on Badoo, CouchSurfing, and Facebook. In the case of Facebook, profile pictures refer to the pictures contained in the folder called "profile pictures", not pictures uploaded to other folders or pictures in which the users are tagged. Likewise, I only gathered the textual information disclosed by participants in their profiles as expressed in the sections "Interests" in CouchSurfing and Badoo, "Groups" in CouchSurfing and Facebook, "Personal Description" in CouchSurfing, and "About me" in Badoo and 
Facebook. I gathered all the information manually and created a file for each participant and network in a Word format. Hine (2015) finds it problematic to analyse data recorded in files instead of analysing it online because, she argues, this practice may disembed the researcher from the setting. In addition, she believes that, in order to understand digitallymediated practices, it is not only interesting to analyse user profiles, but also to observe directly how users interact through social media, as Miller (2011) did in his research on Facebook in Trinidad. In my study, due to the sensitive topic, I found it quite difficult that participants were going to collaborate in logging observation. There was only one participant who insisted on showing me her Badoo account, so that I could have an idea of the number of messages she received and the content and tone of those messages.

\section{Conclusion}

This paper has presented how I designed and conducted a research project about intimacy practices across different social media platforms called "Intimacy in the age of social media". My epistemology is based on the feminist standpoint that "all knowledge is situated" and draws on an ethnographic perspective. I have engaged in reflexivity to analyse the way that I, as a researcher, acquired knowledge and to understand how my personal background and experience affected the research process by explaining my research choices. The research design of this project is based in a multi-sited qualitative case study. The concept of multi-sitedness is helpful to understand how intimacy practices facilitated through social media platforms may occur online or offline and in different locations. This study focuses on three social media platforms: Badoo, CouchSurfing and Facebook. The different kinds of personal relationships these sites foster and facilitate are useful for mapping and understanding the different kinds of intimacy practices that users may experience through social media. In order to approach these practices among adults, I targeted users aged 25-49 years old in Barcelona (Spain) and Leeds (UK). A cross-platform research design is useful to explore broadly the role that different social media technologies play in adults' personal relationships from a twofold approach: (1) The role of social media platforms as intimacy mediators and (2) how adults adopt and adapt technical affordances that these sites provide to create and develop personal relationships.

I used mainly in-depth interviews to collect data, complemented with user profiles analysis and participant observation. The data gathered in the interviews and through participant observation were combined with the information collected from user profiles. Triangulation allows the verification of data and the enrichment of data gathered from one method with data gathered from a different method. For instance, the analysis of users' profiles was useful to verify what participants explain in the interviews and what was actually there. Data directly observed in profiles are more reliable than information reported in interviews, mainly due to the inability of users to remember all the data they have included in their profiles or the privacy options they had applied. I compared the information gath- 
ered through the pre-info sheet and during the interviews with the information actually disclosed in profiles. This helped me to understand how users negotiate the disclosure of what I call "intimacies of digital identity" - that is, what kind of intimate information (both visual and textual) users disclose through their profile(s). In this way, I was able to identify what kind of data participants disclosed through their profiles and which data they considered to be intimate. Why they decided to publish intimate information online was discussed during the interviews. The data gathered through these methods was analysed thematically although the discussion of the use of this method is outside of the scope of this article. The interplay of the data gathered through different methods across different platforms was very helpful to arrive to a holistic understanding of intimacy mediated practices in the age of social media.

\section{Notes}

1 Confessional tales are autobiographical self-reflective accounts used to complement fieldwork reports (Van Maanen, 1998).

\section{References}

Ardèvol, E., \& Gómez-Cruz, E. (2014). Digital ethnography and media practices. The International Encyclopedia of Media Studies.

Beninger, K., Fry, A., Jago, N., Lepps, H., Nass, L., \& Silvester, H. (2014). Research using social media: Users' views. NatCen Social Research. Retrieved November 10, 2014, from http://www.natcen.ac.uk/media/282288/ p0639-research-using-social-media-report-final-190214.pdf.

Berg, B. (2009). Qualitative Research Methods for the Social Sciences. London: Pearson Education.

Borgatti, S. P., \& Molina, J.L. (2005). Toward ethical guidelines for network research in organizations. Social Networks, 27(2), 107-117. DOI:10.1016/j.socnet.2005.01.004

boyd, d. (2014). It's Complicated: The Social Lives of Networked Teens. Yale: University Press.

boyd, d. (2010a). Social network sites as networked publics: Affordances, dynamics, and implications. In Z. Papacharissi (Ed.), Networked Self: Identity, Community, and Culture on Social Network Sites (pp. 39-58). London: Routledge.

boyd, d. (2010b). Friendship. In M. Ito et al. (Eds.), Digital Research Confidential: The Secrets of Studying Behavior Online (pp. 79-115). Cambridge, MA: MIT Press.

Bryman, A. (2012). Social Research Methods. Oxford: Oxford University Press.

Büscher, M., \& Urry, J. (2009). Mobile methods and the empirical. European Journal of Social Theory, 12(1), 99-116.

Cooper, D. (2007). Well, you go there to get off: Visiting feminist care ethics through a women's bathhouse. Feminist Theory, 8(3), 243-262. DOI: 10.1177/1464700107082364.

Couldry, N. (2011). The necessary future of the audience ... and how to research it. In V. Nightingale (Ed.), Handbook of Media Audiences (pp. 213-229). Cambridge, MA: Blackwell.

Dörnyei, Z. (2007). Research Methods in Applied Linguistics. New York, NY: Oxford University Press. 
Ellison, N., Heino, R., \& Gibbs, J. (2006). Managing impressions online: Self-presentation processes in the online dating environment. Journal of Computer-Mediated Communication, 11(2), 415-441. DOI: 10.1111/j.1083-6101.2006.00020.x

Ess \& AoIR Ethics Working Committee (2002). Ethics Guide. Retrieved October 15, 2012, from: www.aoir. org/reports/ethics.pdf.

Ess, C. (2012). Foreword. In D. Heider, \& A. Massanari (Eds.), Digital Ethics: Research \& Practice (Digital Formations) (pp. IX-XIX). New York: Peter Lang.

Falzon, M.A. (2009). Introduction: Multi-sited ethnography. In Mark-Anthony Falzon (Ed.), Multi sited Ethnography: Theory, Praxis and Locality in Contemporary Research. London: Ashgate.

Farrokhi, F., \& Mahmoudi-Hamidabad, A. (2012). Rethinking convenience sampling: Defining quality criteria. Theory and Practice in Language Studies. 2(4), 784-792.

Ferreday, D. (2013). Afterword: Digital relationships and feminist hope. In K. Orton-Johnson, \& N. Prior (Eds.), Digital Sociology: Critical Perspectives (pp. 51-60). Houndmills: Palgrave Macmillan.

Finch, J. (1993). "It's great to have someone to talk to": Ethics and politics of interviewing women. In M. Hammersley (Ed.), Social Research: Philosophy, Politics and Practice (pp.166-180). London: Sage Publications.

Gajjala, R. (2003). South Asian digital diasporas and cyberfeminist webs: Negotiating globalization, nation, gender and information technology design. Contemporary South Asia, 12(1), 41-56.

Gehl, R.W. (2014). Reverse Engineering Social Media: Software, Culture, and Political Economy in New Media Capitalism. Philadelphia, Pennsylvania: Temple University Press.

Gray, D.E. (2009). Doing Research in the Real World. London: Sage.

Hine, C. (2000). Virtual Ethnography. London: Sage.

Hine, C. (2015). Ethnography for the Internet: Embedded, Embodied and Everyday. London: Bloomsbury Publishing.

Hogan, B. (2010). The presentation of self in the age of social media: Distinguishing performances and exhibitions online. Bulletin of Science, Technology \& Society. 30(6), 377-386. DOI: 10.1177/0270467610385893.

Horst, H.A., \& Miller, D. (2013). Digital Anthropology. London: Berg.

Jamieson, L. (2012). Intimacy as a concept: Explaining social change in the context of globalisation or another form of ethnocentricism? Sociological Research Online.. 1(1). Retrieved February 9, 2013, from http:// clarion.ind.in/index.php/clarion/article/view/11

Kalinowski, C., \& Matei, S. A. (2011). Goffman meets online dating: Exploring the "virtually" socially produced self. Journal of Social Informatics, 16, 6-20. Retrieved October 15, 2014, from http://www.ris.uvt.ro/wpcontent/uploads/2012/01/ris16adam.pdf.

Kember, S., \& Zylinska, J. (2012). Life after New Media: Mediation as a Vital Process. Cambridge, MA: MIT Press.

Law, J. (2004). After Method: Mess in Social Science Research. New York: Routledge.

Marcus, G. (1995). Ethnography in/of the world system: The emergence of multi-sited ethnography. Annual Review of Anthropology, 24, 95-117.

Markham, A.N. (1998). Life Online: Researching Real Experience in Virtual Space. Walnut Creek, CA: Rowman Altamira.

Markham, A.N., \& Baym, N.K. (Eds.). (2008). Internet Inquiry: Conversations about Method. Los Angeles: Sage Publications.

Markham, A., \& Buchanan, B. (2012). Ethical decision-making and Internet research. Recommendations from the AolR Ethics Working Committee.

Massey, D. (1992). Politics of space/ time. New Left Review, 196, 65-84.

Madianou, M., \& Miller, D. (2013). Polymedia: Towards a new theory of digital media in interpersonal communication. International Journal of Cultural Studies, 16(2), 169-187. DOI: 10.1177/1367877912452486 
Merriam, S.B. (1998). Qualitative Research and Case Study Applications in Education. San Francisco, CA: Jossey-Bass.

Miller, H. (1995). The presentation of self in electronic life: Goffman on the Internet. Paper presented at Embodied Knowledge and Virtual Space Conference, College, University of London, June, 1995. Retrieved October 10, 2014, from http://www.dourish.com/classes/ics234cw04/miller2.pdf.

Miller, D., \& Slater, D. (2000). The Internet: An Ethnographic Approach. London: Berg.

Miller, D. (2011). Tales from Facebook. Cambridge: Polity.

Morgan, D. (2011). Rethinking Family Practices. Basingstoke: Palgrave Macmillan.

Nissenbaum, H. (2010). Privacy in Context: Technology, Policy, and the Integrity of Social Life. Stanford, CA: Stanford Law Books.

Orgad, S. (2005). The transformative potential of online communication: The case of breast cancer patients' Internet spaces. Feminist Media Studies, 5(2), 141-161.

Pink, S., Horst, H., Postill, J., Hjorth, L., Lewis, T., \& Tacchi, J. (2015). Digital Ethnography: Principles and Practice. London: Sage Publications.

Rainie, L., \& Wellman, B. (2012). Networked: The New Social Operating System. Cambridge, MA: MIT Press.

Reinharz, S., \& Davidman, L. (1992). Feminist Methods in Social Research. Oxford: Oxford University Press.

Renzetti, C.M., \& Lee, R.M. (1993). Researching Sensitive Topics. London: Sage Publications.

Robinson, L., \& Schulz, J. (2009). New avenues for sociological inquiry evolving forms of ethnographic practice. Sociology, 43(4), 685-698.

Rybas, N. \& Gajjala, R. (2007). Developing cyberethnographic research methods for understanding digitally mediated identities. Forum Qualitative Sozialforschung/Forum: Qualitative Social Research, 8(3). Retrieved June 10, 2014, from http://www.qualitative-research.net/index.php/fqs/article/view/282/620

Sannicolas, N. (1997). Erving Goffman, dramaturgy, and on-line relationships. Cibersociology. Site. Retrieved October 10, 2014, from http://www.cybersociology.com/files/1_2_sannicolas.html

Senft, T.M. (2008). Camgirls: Celebrity and Community in the Age of Social Networks. New York, NY: Peter Lang.

Sieber, J.E. (2010). Life is short, ethics is long. Journal of Empirical Research on Human Research Ethics: An International Journal, 5(4), 1-2. DOI: 10.1525/jer.2010.5.4.1.

Sin, C.H. (2003). Interviewing in "place": The socio-spatial construction of interview data. Area, 35(3), 305312.

Skeggs, B. (1995). Feminist Cultural Theory: Process and Production. Manchester: Manchester University Press.

Stanley, L., \& Wise, S. (1993). Breaking Out Again: Feminist Ontology and Epistemology. London: Routledge.

Sumiala, J., Hjelmb, T., Tikkaa, M., and Suurpääc, L. (2014). Studying youth in the media city: Multi-sited reflections. EASA Media Anthropology Network's 46th e-Seminar 25 February/11 March 2014. Retrieved July 12, 2013 from http://www.media-anthropology.net/file/sumiala_etal_youthmediacity.pdf

Turkle, S. (1996). Life on the Screen: Identity in the Age of the Internet. London: Weidenfeld \& Nicolson.

Van Maanen, J. (1988). Tales of the Field: On Writing Ethnography. Chicago, IL: The University of Chicago Press.

Watts, J. (2006). "The outsider within": Dilemmas of qualitative feminist research within a culture of resistance. Qualitative Research. 6(3), 385-402.

Wessels, B. (2012). Identification and the practices of identity and privacy in everyday digital communication. New Media \& Society, 14(8), 1377-1396. DOI: 10.1177/1461444812450679.

Wiles, R. (2013). What Are Qualitative Research Ethics? London: Bloomsbury Academic. Yin, R.K. (2009). Case Study Research: Design and Methods. Thousand Oaks, CA: Sage Publications. Yin, R.K. (2013). Case Study Research: Design and Methods. Los Angeles, CA: Sage Publications. 
Article: Researching intimacy through social media

Cristina Miguel

Senior Lecturer, PhD

School of Strategy, Marketing and Communication

Leeds Beckett University

C.Miguel@leedsbeckett.ac.uk 